\title{
UNIDADE DE TERAPIA INTENSIVA NEONATAL: RISCOS FÍSICOS COMO FATORES POTENCIAIS DE AGRAVOS À SAÚDE DO TRABALHADOR
}

\section{NEONATAL INTENSIVE CARE UNIT: PHYSICAL RISK AS POTENTIAL FACTORS OF INJURIES FOR HEALTH WORKERS}

\author{
Livia Maria Nunes de Almeida ${ }^{1}$ \\ Milton Beltrame Junior ${ }^{2}$ \\ Maria Belén Posso Salazar ${ }^{3}$
}

Resumo: As UTIN constituem-se em setores onde são internados recém-nascidos em estado grave, em situações de risco, que necessitam de recursos técnicos e humanos especializados para sua recuperação, exigindo uma abordagem integral da saúde por uma equipe multidisciplinar, cujos membros estão expostos a riscos ambientais e ocupacionais diariamente. No Brasil, há inúmeros convênios e recomendações da Organização Internacional do Trabalho (OIT), aprovados pelas Normas Regulamentadoras (NR32), por intermédio do Ministério do Trabalho que têm como objetivo eliminar ou controlar os riscos ocupacionais. Este artigo teve por objetivo geral identificar as fontes potenciais dos riscos físicos presentes em uma UTIN localizada no interior do estado do Maranhão, capazes de gerar acidentes de trabalho e doenças ocupacionais. O método utilizado foi descritivo e exploratório, de campo, transversal com abordagem quantitativa. Os resultados apontaram como principais agravantes para os riscos a acidentes de trabalho: o teto com rachaduras, pisos de cor escura e sem proteção antiderrapante, armários e outros mobiliários em má conservação e instalações elétricas inadequadas. Quanto aos riscos físicos foram identificados o excesso de ruídos, o calor e a radiação. Concluiu-se ser necessário o desenvolvimento de estudos que discutam os riscos a que os profissionais da saúde da UTIN estão expostos e suas implicações, de modo a oferecer segurança a esses profissionais durante suas atividades laborais, possibilitando, consequentemente, a prestação de uma assistência de qualidade.

Palavras-chave: Unidade de Terapia Intensiva; recém-nascido; riscos ocupacionais.

\begin{abstract}
NICUs are sectors where newborns are hospitalized who are in serious condition, at risk, and need specialized technical and human resources for their recovery. This requires a holistic approach to health by a multidisciplinary team, who are daily exposed to environmental and occupational risks. In Brazil, there are numerous conventions and recommendations of the International Labor Organization (ILO), approved by the Regulatory Standards (NR32), through the Ministry of Labor, which aims to eliminate or control occupational hazards. This article aims to identify potential sources of physical hazards present in a NICU located in Maranhão state, which are capable of causing accidents at work and occupational diseases. The method used was a descriptive and exploratory, in the field, cross-sectional quantitative approach. Results showed that the main aggravating risks of industrial accidents were the ceiling with cracks, dark floors without slip protect, cabinets and other furniture in disrepair, and inadequate electrical installations. The physical hazards identified include excess noise, heat, and radiation. We found the need to develop more studies that discuss the risks that health professionals in the NICU are exposed and their implications, in order to provide security to these professionals during their job activities, enabling them to provide quality service.
\end{abstract}

Keywords: Intensive Care Unit; newborn; occupational hazards.

\footnotetext{
1 Mestre em Bioengenharia - Universidade Vale do Paraíba - Univap e Enfermeira da Secretaria Municipal de Saúde de Caxias MA. E-mail: liviaalmeida24@hotmail.com.

2 Doutor em Química - Universidade de São Paulo - USP e Docente da Univap. E-mail: beltrame@univap.br.

${ }^{3}$ Doutora em Enfermagem - USP e Docente da Univap. E-mail: mbelen@terra.com.br.
} 


\section{INTRODUÇÃO}

O ambiente e as condições físico-funcionais do local onde o trabalho se realiza podem gerar impactos e repercussões de diversas naturezas nas atividades dos trabalhadores, seja nos aspectos políticos, econômicos e sociais (MENDES, 2003). E o ambiente das Unidades de Terapia Intensiva (UTI), em especial as Unidades de Terapia Intensiva Neonatal (UTIN) não fogem à regra, motivando preocupações, discussões e investigações de toda sociedade sobre esse fenômeno (MENDES, 2003).

Como afirmam Nishide, Benatti e Alexandre (2004) e conforme encontrado em Brasil (2011), - Estabelecimento de Assistência à Saúde (EAS) é um cenário de trabalho em que são desempenhadas atividades e procedimentos com variável complexidade e potencialidade de riscos capazes, dependendo da gravidade, de causar "lesão corporal ou distúrbio funcional, permanente ou temporário, morte e a perda ou a redução da capacidade para o trabalho".

Nesse contexto, o ambiente de trabalho hospitalar e, por consequência o das UTIN, é considerado insalubre, pois, ao mesmo tempo em que abriga pacientes portadores de diversas enfermidades, sejam elas infectocontagiosas ou não, também, o manuseio de tecnologia sofisticada e o desempenho de atividades profissionais, podem gerar riscos de acidentes e doenças do trabalho para a equipe de saúde (NISHIDE; BENATTI; ALEXANDRE, 2004). Tendo em vista os múltiplos riscos a que estão expostos os profissionais de saúde em UTIN e as constantes preocupações em relação às condições de trabalho nesses ambientes, justifica-se o despertar para o conhecimento desse problema.

Tais observações impulsionaram o interesse em desenvolver uma pesquisa sobre os riscos físicos aos quais os trabalhadores estão expostos em ambiente de UTIN, tendo, como objetivos gerais, verificar as condições físico-funcionais de uma Unidade de Terapia Intensiva Neonatal frente às recomendações da RDC 50/ANVISA/2002 e identificar as fontes potenciais dos riscos físicos presentes em um UTIN, do interior do Estado do Maranhão, capazes de gerar acidentes de trabalho e/ou doenças ocupacionais.

Dessa forma, estudos que tenham como objetivos o conhecimento dos riscos ocupacionais entre os trabalhadores de Enfermagem são de grande relevância, pois irão contribuir para que os profissionais de saúde reconheçam os riscos físicos, aos quais estão expostos, almejando, assim, maior segurança para o trabalhador no ambiente laboral e, consequentemente, qualificação na assistência prestada por esses profissionais.

\section{REFERENCIAL}

O ambiente intra-uterino possui condições ideais para o crescimento e desenvolvimento fetal, possuindo características especiais, como "temperatura agradável e constante, maciez, aconchego e os sons extra-uterinos são filtrados e diminuídos" (REICHERT; LINS; COLLET, 2007). Já, na UTIN, o RN vivencia uma ambiência bastante diferente daquela encontrada no útero, impregnada de estímulos luminosos, de ruído, temperatura ambiental inconstante, entre outros (REICHERT; LINS; COLLET, 2007). 
A necessidade de internação em uma UTI Neonatal nem sempre significa bemestar físico e emocional para o paciente. Ao se considerar que a adaptação ao ambiente normal, ao lado da mãe, já é complexa e difícil para um bebê, o neonato experimenta maior estresse ao tentar se adaptar a um ambiente desconhecido e hostil, e, ainda, ser afastado daqueles que conhece. Esse ambiente desconhecido com intensa luminosidade, ruidoso, com manipulação constante e estando submetido a procedimentos invasivos dolorosos, trazem-lhe extremo desconforto físico e mental (COSTENARO, 2008).

Montanholi, Merighi e Jesus (2001) afirmam que a sistematização da assistência e o uso de protocolos para manejo dos recursos tecnológicos, acrescidos de educação permanente favorecem e capacitam a ação profissional de qualidade. Enfatizam, ainda, a importância da capacitação para ministrar os cuidados diretos aos RN internados em uma UTIN, conscientizando enfermeiros e gestores das EAS para uma assistência de alta qualidade a um paciente tão fragilizado (MONTANHOLI; MERIGHI; JESUS, 2001).

Os funcionários que trabalham nas instituições hospitalares estão expostos a riscos ambientais que podem ser classificados em físicos, químicos, biológicos e psicológicos, variando de acordo com o seu agente etiológico (BRASIL, 2005).

Os riscos físicos, de acordo com as Normas Regulamentadoras NR-09 e NR-15, são os riscos aos quais os trabalhadores estão expostos que se associam às formas de energia, podendo ter como agentes causadores: ruídos, vibrações, pressões anormais, radiações ionizantes e não ionizantes, ultra-som e infra-som (BRASIL, 2005a).

Os acidentes e doenças do trabalho podem advir quando não observados os limites de tolerância e as normas de segurança, resultando em potencial gravidade nas atividades executadas (COSTA; COSTA; NELO, 2008).

Acidente de trabalho é considerado aquele que "ocorre pelo exercício do trabalho a serviço da empresa, provocando lesão corporal ou perturbação funcional, que cause morte, perda ou redução, permanente ou temporária, da capacidade para o trabalho" (BRASIL, 2005). Ainda, segundo a Consolidação das Leis do Trabalho - CLT (BRASIL, 2005), são categorizados como acidentes de trabalho, os seguintes: acidentes típicos, acidentes de trajeto, doenças profissionais e doenças do trabalho.

Assim, os acidentes de trabalho podem ocorrer, dependendo das situações de trabalho cujas condições apresentam potencialidade de causar danos aos trabalhadores pelos mais variados fatores causais, tais como: exíguo espaço de movimentação; pisos lisos e escorregadios, ambientes ruidosos, manutenção inadequada de equipamentos, entre outros (BRASIL, 2005).

\section{METODOLOGIA}

\subsection{Tipo de Estudo}

Levando em consideração os objetivos propostos, optou-se pelo desenvolvimento de uma pesquisa do tipo descritivo e exploratório, de campo e transversal com abordagem quantitativa. 


\subsection{Local da Pesquisa}

O estudo foi realizado em uma maternidade pública, de médio porte, situada em um município do Maranhão, que possui 75 leitos, dos quais 10 são leitos de UTIN. A escolha desse estabelecimento procedeu-se por ser considerado de referência para o atendimento de $\mathrm{RN}$ de risco na macrorregião do referido município. Para proceder à pesquisa, foi realizado o convite a esse estabelecimento de saúde, mediante o envio da solicitação de coleta de dados e anexada cópia do projeto de pesquisa. Após o aceite, procedeu-se a coleta de dados na UTIN do referido estabelecimento de saúde, que, além da disponibilidade em oferecer suas dependências, favoreceu a operacionalização da coleta.

\subsection{Coleta dos Dados}

Por ser a UTIN um ambiente dinâmico, com picos horários de maior atendimento, exigindo mais atenção por parte dos funcionários, a coleta de dados foi realizada após o estabelecimento de horários pela coordenação do setor, de modo que a pesquisa não interferisse com o processo de trabalho e a rotina da unidade.

A metodologia deste trabalho foi desenvolvida em duas etapas, sendo a primeira, um momento de observação e a segunda um mapeamento da área em estudo mediante utilização da planta física baixa e do instrumento de identificação de riscos físicos. Essa etapa teve como objetivo conhecer as atividades desenvolvidas na unidade, quanto à assistência prestada aos clientes, com a finalidade de identificar a presença de fontes potenciais de riscos físicos às quais está exposta a equipe de saúde do referido estabelecimento.

A segunda etapa teve como objetivo o mapeamento da área da UTIN e a coleta de dados para a identificação das fontes potenciais de riscos físicos presentes no estabelecimento em estudo. Nessa fase, os instrumentos utilizados foram: uma máquina fotográfica da marca Samsung, uma trena de 30 metros, um aparelho denominado termo-higro-decibelímetro-luxímetro, modelo THDL400, da marca Instrutherm, além do instrumento para a identificação de riscos físicos, que foi fundamentado na literatura nacional e internacional, tendo como referenciais teóricos a RDC50/ANVISA/2002 (BRASIL, 2002), Posso (1988), Benedett (2008) e em observações advindas da atividade profissional da pesquisadora em UTIN que forneceu informações para a confecção do instrumento, relevantes para este estudo. Este instrumento é constituído de três partes: parte 1, contendo dados sobre a caracterização da UTIN; parte 2, referente às características estruturais dessa unidade; e parte 3 , mostrando os potenciais riscos físicos existentes na unidade.

Para a coleta, foram selecionados 06 pontos distintos na UTIN: posto de Enfermagem, sala de cuidados e higienização do RN, sala de preparo de medicações e três pontos próximos aos leitos.

A coleta de dados foi realizada no mês de abril de 2013, pela própria pesquisadora, por meio do instrumento de coleta de dados, no período vespertino. No momento da coleta, houve total colaboração da equipe de enfermagem presente, o que possibilitou a obtenção de informações de itens referentes às características gerais e classificação do estabelecimento quanto ao tipo de mantenedora, sua finalidade e porte, e aos tipos de serviço de manutenção. 


\subsection{Procedimentos Éticos}

Considerando as exigências formais contidas na Resolução 196/96 (BRASIL, 1996), o projeto de pesquisa foi submetido à avaliação do EAS a ser pesquisado, que emitiu parecer favorável à realização da mesma. Foi assegurado o anonimato e o direito de se retirar da pesquisa se assim o desejasse, protegendo sua identidade e a privacidade de todos os envolvidos.

\section{RESULTADOS E DISCUSSÃO}

A equipe que atua na UTIN é composta por: 02 médicos, 07 enfermeiros, 25 técnicos de enfermagem. Além de profissionais que prestam apoio, tais como: 02 fisioterapeutas, 01 nutricionista, 01 psicólogo e 02 assistentes sociais.

A manutenção técnica é mista, isto é, possui técnicos do quadro do EAS e técnicos contratados, caracterizando a terceirização. A manutenção é realizada preventiva e corretivamente, cujos responsáveis por ela apresentam ensino médio completo. Tal situação difere dos dados de Benedett (2008), cujo tipo de manutenção é apenas corretivo, o que não é indicado.

Benedett (2008) enfatiza que, para a assistência prestada ao indivíduo doente seja qualificada, são necessários: "recursos materiais, uma eficiente estrutura física, planejamento e organização de suas atividades, bem como uma estrutura adequada em relação aos recursos humanos". Então, foi possível identificar a área total da UTIN pesquisada corresponde a 110,45 m², incluindo a área de preparo de medicação, cuidado com o RN, leito de isolamento e posto de enfermagem interno. Esses dados estão de acordo com os padrões exigidos pela RDC ANVISA no 50/2002 (BRASIL, 2002). A distribuição das áreas entre os leitos na UTIN em m² varia entre 3,46 $\mathrm{m}^{2}$ a 5,04 $\mathrm{m}^{2}$. Possui, também, um leito especial, denominado de leito de isolamento que apresenta uma área de 7,35 m². O espaço entre as incubadoras varia entre 0,81 e 3,74 m.

Constatou-se que as medições da área de cada leito da UTIN corresponde aos parâmetros recomendados pelo Ministério da Saúde (MS), pelas Portarias no 400/12/1977 (BRASIL, 1977) e do MS no 1884/11/1994 (BRASIL, 1994), além da Resolução Colegiada do MS/ANVISA/RDC 50/2002 (BRASIL, 2002) que preconizam que a área destinada a cada incubadora de RN prematuros deve possuir 2,50 $\mathrm{m}^{2}$, devendo haver uma distância entre elas de, no mínimo, $1 \mathrm{~m}$. Um fato que chamou a atenção está relacionado a dois leitos com espaços abaixo da média preconizada, apresentando a distância de 0,81 e 0,84 m.

Esses achados diferem dos encontrados na pesquisa de Saraiva (2004) que constatou que a UTIN avaliada possuía uma boa disposição física entre os berços e que todos estavam de acordo com as normas vigentes. De acordo com Benedett (2008), a não adequação dos espaços entre os leitos é decorrente da falta de planejamento e dimensionamento de espaço interno, além do não cumprimento das normas ministeriais, o que pode ocasionar um aumento dos riscos aos trabalhadores durante suas atividades, devido à falta de espaço para a sua execução.

Foram identificadas várias fontes potenciais de risco físico em relação à estrutura física da UTIN em questão, tais como: teto e paredes com rachaduras, presença de coluna de sustentação com risco de colisão, piso escorregadio, apresentando áreas não íntegras próximo ao rodapé. Os 
problemas de integridade presentes no teto podem apresentar o risco de desmoronamento de fragmentos, podendo atingir os trabalhadores, visitantes, entre outros que transitam por esse espaço, causando-lhes agravos à saúde. Resultado diferente foi encontrado por Saraiva (2004), em seu estudo na UTIN de Novo Hamburgo, em que "as paredes e o teto estavam em boa conservação, sendo pintados de tinta fosca e lavável".

Outro problema na estrutura física é a existência de uma coluna de sustentação entre o posto de enfermagem e os berçários, a qual dificulta a visualização de alguns leitos, propiciando que os profissionais estejam constantemente levantando-se para monitorá-los, podendo ocasionar maior desgaste físico a esses funcionários.

Foram avaliados alguns materiais e equipamentos, dentre eles: painel, negatoscópio e os mobiliários. No painel, há rede de gases com 3 fluxômetros: um de $\mathrm{O}_{2}$, um de vácuo e um de ar comprimido, cada rede possuindo 09 saídas, todas funcionantes e fixas, com altura de 1,40 m do solo, obedecendo às recomendações pertinentes (BRASIL, 2002). Já, o negatoscópio não estava obedecendo às normas vigentes, pois sua estrutura de fixação apresentava-se saliente, a uma altura de 1,13 m do piso, o que oferece risco de contusão aos funcionários.

Quanto aos equipamentos eletromédicos, alguns não estavam em uso, porém, encontravamse dispostos entre os leitos, dificultando a assistência aos pacientes. Alguns armários encontravamse em más condições de conservação e, ainda, possuíam quinas, que poderiam ser responsáveis por contusões na equipe que ali presta assistência.

Ainda foram avaliados iluminação, umidade, temperatura, ruídos e radiações ionizantes e não ionizantes. O Índice de iluminação foi avaliado em 6 pontos: na sala de preparo de medicação foi encontrado o índice de 280 lux; na área de cuidado e higienização, 390 lux; nos pontos próximos às incubadoras, foram encontrados 28, 89 e 110 lux; no posto de enfermagem, 57 lux. Esses dados estão aquém do estabelecido para ambientes de trabalho onde a inspeção e a precisão devem ser exercidas, pois recomenda-se que, em todos os locais de trabalho deve haver iluminação adequada, natural, ou artificial, geral ou suplementar apropriada à natureza da atividade (BRASIL, 2001). A esse respeito a NR 17 trata claramente a questão da iluminação e recomenda, pela NBR 5413/1992 da Associação Brasileira de Normas Técnicas (ABNT, 1992), que os níveis mínimos de iluminação para os ambientes de trabalho hospitalar devem estar entre 300 e 750 lux, sendo que a área de cuidado e higienização onde se realiza o exame físico do RN, com a inspeção da pele, seus anexos, sua coloração, entre outros sinais, deve ser em torno de 500 lux (SOBECC, 2009), com o que concorda Benedett (2008).

Os valores de nível de pressão sonora (NPS) encontrados na sala de preparo de medicação, na área de cuidado e higienização e no posto de enfermagem, foram iguais, sendo encontrado o valor de 57,4 dBA. Foi mensurado o NPS em três pontos diferentes próximos às incubadoras, quais sejam: 10 ponto: no momento da aferição, encontravam-se um monitor cardíaco, o respirador e a bomba de infusão conectados; no 2 o ponto, o valor encontrado foi de $57,4 \mathrm{dBA}$; e, no 3 ponto, de 86,4 dBA. Sendo que, em média, o NPS foi de 71,9 dBA, bem acima do recomendado pela Legislação vigente.

Revista Univap - revista.univap.br

São José dos Campos-SP-Brasil, v. 20, n. 35, jul.2014. ISSN 2237-1753 
De acordo com as regulamentações para os NPS compatíveis com o conforto acústico nos diversos ambientes, a Norma Brasileira (NBR) 10152 fixa que: os níveis devem ficar entre "35 a 45 dBA em apartamentos, enfermarias, berçários e centros cirúrgicos". Entende-se que valores superiores a esses representam nível sonoro desconfortável (ABNT, 1987). Segundo a RDC 50/2002 (BRASIL, 2002), a exposição a esses níveis, variando entre 85 a 110 dBA, por períodos de tempo relativamente curtos, podem afetar o sistema nervoso, o aparelho digestivo e circulatório, levando a sensações de desconforto e fadiga.

A umidade relativa do ar e a temperatura apresentaram valores médios de $49,5 \%$ e $30,9^{\circ} \mathrm{C}$, respectivamente. Em relação à umidade os dados encontrados estão próximos ao limite mínimo preconizado pela legislação pertinente (BRASIL, 2002). No entanto, no que tange à temperatura, vale destacar que se apresentava muito superior ao determinado que é de $19{ }^{\circ} \mathrm{C}$ a $24^{\circ} \mathrm{C}$ (BRASIL, 2002), isto deveu-se ao fato de problemas com a climatização, que estava defeituosa (em média $26^{\circ} \mathrm{C}$ ), podendo causar alterações fisiológicas e comportamentais nos pacientes e equipe.

Quanto à radiação ionizante e não-ionizante a UTIN pesquisada, apresenta 7 aparelhos emissores de radiação, sendo 01 raios $X$ portátil e 06 aparelhos de fototerapia. Nessa unidade, não existe proteção de chumbo nas paredes, nas portas e, tampouco, nos vidros. Outro ponto observado foi que não existe proteção especial para os profissionais que circulam nessa unidade, só há avental de chumbo para o profissional que executa o exame de raio-X. Os demais profissionais, no momento desse tipo de exame, retiram-se do local de exposição, cuidado comum no meio hospitalar, porém, que não os exime de receber a radiação, posto que o afastamento costuma ser próximo ao local irradiado.

A Portaria MS 453/1998 (BRASIL, 1998), que enfatiza as recomendações para a realização de exames radiológicos com equipamentos móveis em leitos hospitalares ou em ambientes coletivos de internação, pontua que "os demais usuários que não puderem ser removidos do ambiente devem ser protegidos da radiação espalhada por uma barreira protetora com, no mínimo, $0,5 \mathrm{~mm}$ de equivalência de chumbo; ou, posicioná-los de modo que nenhuma parte do corpo esteja a menos de dois metros do cabeçote ou do receptor de imagem".

Sobre as instalações elétricas, vale ressaltar, também, que para cada incubadora existe apenas uma tomada. Isso leva os profissionais a conectarem vários aparelhos, de forma insegura e arriscada, em extensões, o que pode ocasionar uma sobrecarga elétrica e, por conseguinte, o choque elétrico nos trabalhadores que entram em contato com as incubadoras. Posso (1988) comenta que a gravidade do choque elétrico é maior quando atravessa o coração, podendo ocasionar fibrilação cardíaca, contrações musculares intensas com quedas, contusões e queimaduras graves.

Foi possível identificar, durante a pesquisa, ainda, a utilização de uma única extensão para duas incubadoras, o que, além de proporcionar risco de choques mencionados anteriormente, expõem os trabalhadores a outros problemas decorrentes da presença de fios soltos e enovelados, entre as incubadoras, podendo ocasionar queda dos funcionários ao transitarem nesses locais, durante a prática assistencial. 


\section{CONCLUSÃO}

Diante da magnitude dos problemas decorrentes da falta de uma estrutura física adequada às normas vigentes da RDC ANVISA no 50/2002 (BRASIL, 2002), na UTIN avaliada, faz-se necessário o desenvolvimento de medidas interventivas urgentes, pois, embora os profissionais que atuam nesse setor estejam desenvolvendo suas atividades de forma continua e ininterrupta, são fundamentais o planejamento e a execução de ações que minimizem ou eliminem os riscos inerentes a esses problemas.

Riscos de acidentes ocupacionais foram identificados pelas paredes e teto com rachaduras, pisos de cor escura e escorregadios sem proteção antiderrapante, móveis sem utilização, em locais inapropriados, e, também, em mau estado de conservação, janelas sem tela e instalações elétricas inadequadas às normas da RDC ANVISA no 50/2002 (BRASIL, 2002).

Ainda, o NPS de 71,9 dBA, apesar de não ultrapassar as recomendações da RDC ANVISA no 50/2002 (BRASIL, 2002), pode, porém, pela constância da exposição, causar estresse e desconforto na equipe. Em relação à temperatura, ela ultrapassa as normas; o risco de radiação ionizante também foi identificado, pois não existe proteção específica nas paredes dessas unidades.

Sendo assim, é necessário o desenvolvimento constante de estudos que abordem os tipos de riscos a que estão sujeitos os profissionais de saúde, em especial os de enfermagem, de forma a avançar no conhecimento sobre riscos ocupacionais no trabalho de enfermagem e ter condições de apresentar evidências sobre esses riscos, de modo a oferecer aos enfermeiros e demais membros da equipe de saúde segurança durante a atividade laboral, possibilitando, consequentemente, a prestação de uma assistência de qualidade.

\section{REFERÊNCIAS}

ASSOCIAÇÃO BRASILEIRA DE NORMAS TÉCNICAS (ABNT). NBR 10.152: Níveis de ruído para conforto acústico. Rio de Janeiro: ABNT, 1987.

NBR 5.413: Iluminância de interiores. Rio de Janeiro: ABNT, 1992.

BENEDETT, A. Riscos físicos: sua potencialidade na Unidade de Terapia Intensiva Neonatal. $63 f$. 2008. Dissertação (Mestrado) Instituto de Pesquisa e Desenvolvimento, Universidade do Vale do Paraíba, São José dos Campos, 2008.

BRASIL. Aspecto de Segurança no Ambiente Hospitalar. Brasília: Ministério da Saúde. 2002.

2005.

Leis, Decretos. Consolidação das leis do trabalho. Porto Alegre (RS): Verbo Jurídico;

Ministério da Saúde. Portaria no 1884/94. GM/MS de 11/11/94. Normas para planejamento Físico de Unidades de Saúde. Brasília, 1994.

Ministério da Saúde. Portaria № 453/98. Diretrizes de Proteção Radiológica em

Radiodiagnóstico Médico e Odontológico. Brasília, 1998.

Revista Univap - revista.univap.br

São José dos Campos-SP-Brasil, v. 20, n. 35, jul.2014. ISSN 2237-1753 
- Ministério da Saúde. Secretaria de Políticas de Saúde. Área de Saúde da Criança. Atenção humanizada ao recém-nascido de baixo peso: método mãe canguru. Manual do Curso. Brasília: Ministério da Saúde, 2011.

Organização Pan-Americana da Saúde no Brasil. Doenças relacionadas ao trabalho: manual de procedimentos para os serviços de saúde. Brasília: Ministério da Saúde, 2001.

COSTA, M. A. F.; COSTA, M. F. B.; NELO, N. S. F. O. Biossegurança: ambientes hospitalares e odontológicos. São Paulo: Santos, 2008.

COSTENARO, R. G. S. Ambiente terapêutico de cuidado ao recém-nascido internado em UTI Neonatal. Santa Maria: UNIFRA. 2008.

MENDES, R. Patologia do trabalho. Rio de Janeiro: Atheneu; 2003.

MONTANHOLI, L. L.; MERIGHI, M. A. B.; JESUS, M. C. P. Atuação da enfermeira na unidade de terapia intensiva neonatal: entre 0 ideal, 0 real e o possível. Rev. Latino-Am. Enfermagem. Ribeirão Preto, v. 19, n. 2, pp. 301-08, mar-abr. 2001.

NISHIDE, V. M.; BENATTI, M. C. C. Riscos ocupacionais entre trabalhadores de enfermagem de uma unidade de terapia intensiva. Rev. esc. enferm. São Paulo, v. 38, n. 4, pp. 406-14, dez. 2004.

POSSO, M. B. S. As fontes de riscos físicos e químicos incidentes sobre os membros da equipe cirúrgica. Tese (Doutorado) - Escola de Enfermagem da Universidade de São Paulo, 1988.

REICHERT, A. P. S.; LINS, R. N. P.; COLLET, N. Humanização do Cuidado da UTI Neonatal. Rev. Eletr. Enf. Rio de Janeiro, v. 9, n. 1, pp. 200-13, maio 2007.

SARAIVA, C. A. S. Fatores físicos ambientais e organizacionais em uma Unidade de Terapia Intensiva Neonatal: implicações para a saúde do recém-nascido. 2004. Dissertação (Mestrado) - Escola de Engenharia da Universidade Federal do Rio Grande do Sul, Porto Alegre, 2004.

SOBECC. Sociedade Brasileira de Enfermeiros de Centro Cirúrgico Recuperação Pós Anestésica e Centro de Material e Esterilização. Práticas Recomendadas da SOBECC, 5. ed. São Paulo: SOBECC, 2009. 